Rev. Adm. Saúde (On-line), São Paulo, v. 19, n. 76: e186, jul. - set. 2019, Epub 10 set. 2019 http://dx.doi.org/10.23973/ras.76.186

EDITORIAL

\title{
Liderança é uma técnica que se aprende e se desenvolve coletivamente; é uma ferramenta de gestão
}

\author{
Haino Burmester ${ }^{1}$
}

1. Médico, administrador hospitalar e de sistemas de saúde. Conselheiro do Programa CQH

"A liderança não é definida pelo exercício do poder, mas pela capacidade de aumentar o sentido de poder entre os liderados." (Mary Parker Follet, 1924)

Quando se fala em liderança, se fala de poder. Poder para fazer coisas acontecerem devido à uma posição hierárquica que a pessoa tenha. Não se está falando de poder como dominação o que é deletério para qualquer instituição. No poder de dominação sempre existem dominadores e dominados. O que se quer em uma instituição saudável e amadurecida são pessoas emponderadas e não dominadas. Esta reflexão nos remete para uma primeira diferenciação importante que deve ser feita entre líderes e chefes, diretores, presidentes ou qualquer outra denominação para posições hierárquicas, cujo poder vem atrelado ao cargo. Uma segunda diferenciação deve ser feita entre líder e gestor. Este é uma pessoa sob cuja responsabilidade são colocados recursos materiais, humanos, financeiros e organizacionais para a execução de uma tarefa visando alcançar algum resultado.

Independentemente das reflexões acima, a liderança pressupõe a existência de dois componentes: um individual e outro coletivo. No individual se destacam as competências de conhecimentos, habilidades e atitudes que os líderes devem ter ou se não as tiverem devem desenvolver. Estas competências irão desenhar um perfil de pessoas comprometidas com resultados; que tenham propósitos definidos nas suas vidas e para as instituições onde atuam; que pratiquem valores baseados em princípios morais, filosóficos ou espirituais; portanto, representem modelos nos quais as pessoas da instituição possam ou queiram se referenciar. E qualquer pessoa na instituição pode desenvolver estas competências e, portanto, todos podem ser líderes. 
Neste artigo se quer colocar ênfase no componente coletivo da liderança. $O$ que se pretende aqui é mudar o modelo mental centrado no líder heroico, mitológico, transformador, carismático, condutor de pessoas que seduz, manipula e impõe sua vontade para conduzir as pessoas. Entende-se que se uma pessoa tem esta capacidade ela conduzirá as pessoas e as instituições para fazerem o que ela quer e não, necessariamente, para aquilo que as organizações necessitam. Basta refletir sobre o que os líderes carismáticos já causaram para o mundo e para as instituições ao longo da história.

Neste sentido se define liderança coletiva como um processo dinâmico em que um grupo de líderes utiliza seletivamente suas experiências e habilidades em rede. Trata-se de uma abordagem emergente a partir da crescente complexidade das instituições atuais que são muito grandes, complexas, com muitas corporações dispondo de informações em quantidades nunca antes disponíveis, que necessitam de respostas rápidas e complexas para se adaptarem às necessidades do mundo atual. As organizações do mundo atual têm que conviver com condições nunca antes experimentadas. Portanto, elas necessitam de equipes de líderes que liderem como nunca antes uma organização foi liderada, compartilhando decisões no mesmo nível hierárquico para responder às demandas institucionais da atualidade. A liderança coletiva significa cada um assumindo suas responsabilidades pelo sucesso da organização como um todo - não apenas do seu emprego ou setor de trabalho. Isso contrasta com a abordagem tradicional de liderança, focada no desenvolvimento de capacidades individuais, negligenciando a necessidade do desenvolvimento da capacidade coletiva ou do desenvolvimento de líderes no contexto da organização em que trabalham.

Os grandes motores das equipes nas organizações são os conceitos básicos dela: a missão ou propósito; sua visão estratégica de futuro; seus valores; e políticas básicas. Neste sentido os líderes são os guardiões e principais disseminadores destes conceitos. Quando todos, pela inércia natural existente em todas as organizações, se afastem deles caberá aos líderes fazerem a instituição voltar aos seus princípios básicos e orientadores de sua ação.

O epicentro da liderança coletiva não é só o papel da liderança formal, mas a interação dos membros de um time para liderá-lo pelo compartilhamento das responsabilidades de liderança. Percepções compartilhadas nas equipes em relação ao quanto de liderança coletiva existe e quanto cada um deve ou pode assumir nelas. Trata-se de um processo de influência dinâmico e interativo no qual indivíduos atuam em grupo com o objetivo de liderar uns aos outros para realizar as metas do grupo, da instituição ou de ambos. É um processo dinâmico no qual um líder definido, ou conjunto de líderes, seletivamente utiliza habilidades e experiências como uma rede, efetivamente distribuindo elementos dos papéis da liderança conforme a situação ou o problema requer, como no conceito de liderança situacional. Todas as grandes instituições públicas ou privadas estão, cada vez mais, absorvendo e praticando estes conceitos como forma de sobrevivência e sustentabilidade.

O King's Fund, organismo privado sem fins lucrativos existente para estudar e propor formas de melhorar o sistema de saúde inglês diz que aquele sistema necessita de liderança do mais alto nível se quiser responder satisfatoriamente 
às pressões assistenciais e financeiras a que está submetido. "O Fundo defende a necessidade de se avançar do conceito de líder herói para o da liderança compartilhada e distribuída por todo o Sistema. Os líderes nesta perspectiva devem engajar seus colegas e demais grupos de interesse se quiserem melhorar o cuidado aos pacientes e transformar a maneira como esse cuidado é prestado". Seguindo esses preceitos pode-se, facilmente, dizer como Lao Tsé na citação abaixo:

"É melhor quando as pessoas mal percebem que o líder existe; não tão bom quando as pessoas o obedecem e aclamam; pior quando o desprezam.... Mas de um bom líder, que fala pouco quando sua tarefa é concluída, seu objetivo alcançado, as pessoas dirão: 'nós mesmos fizemos." (Lao-Tsé, século VI a.C.)

Recebido: 09 de setembro de 2019. Aceito: 10 de setembro de 2019

Correspondência: Haino Burmester. Avenida Brigadeiro Luís Antônio, 278 - $2^{\circ}$ andar. CEP 01318-901. São Paulo - SP. E-mail: cqh@apm.org.br

Conflito de Interesses: os autores declararam não haver conflito de interesses.

(C) This is an Open Access article distributed under the terms of the Creative Commons Attribution License, which permits unrestricted use, distribution, and reproduction in any medium, provided the original work is properly cited 